\title{
Influence of filler-bitumen ratio on performance of modified asphalt mortar by additive
}

\author{
Hongsheng Qiu $\cdot$ Ximing Tan • \\ Shu Shi $\cdot$ Heng Zhang
}

Received: 18 March 2012/Revised: 23 October 2012/ Accepted: 2 November 2012/Published online: 20 June 2013

(C) The Author(s) 2013. This article is published with open access at Springerlink.com

\begin{abstract}
When the filler-bitumen ratio of asphalt mortar changes, its adhesion and viscoelasticity will also change, as well as its mechanical performances, such as fatigue durability at normal temperature and low-temperature ductility. Thus, the filler-bitumen ratio directly affects the asphalt mortar's performance. This paper tested the physical indexes of the No. 70 matrix asphalt mortar modified by additive Sasobit (SB) and Sasowam (SW) through dynamic shear rheometer and bending beam rheometer under different temperature conditions, and comprehensively analyzed the high-temperature anti-rutting and fatigue performance, low-temperature crack resistance performance, and ductility of asphalt mortar. The results show that ore powder not only can increase the anti-rutting factor but also can increase the aging resistance of asphalt. SB has better performances than SW at high temperatures. As for the filler-bitumen ratio of asphalt mortar with additive SB, the recommended value is between 0.8 and 1.2 , and the value may be a little larger for that with SW.
\end{abstract}

Keywords Filler-bitumen ratio - Asphalt mortar - Antirutting factor $\cdot$ Small beam specimens $\cdot$ Creep rate

\section{Introduction}

Asphalt is often the choice of highway pavement material in the world. With the traffic growth, the overloaded vehicles will cause the early damage of asphalt pavement, including high-temperature rutting, low-temperature cracks, subsidence, potholes, etc. Mortar theory assumes that asphalt

H. Qiu $(\bowtie) \cdot X$. Tan $\cdot$ S. Shi $\cdot$ H. Zhang

School of Transportation, Wuhan University of Technology,

Wuhan 430063, China

e-mail: 13377889059@163.com mixture is a dispersed system of multilevel interspace reticulate structure with coarse aggregate as the dispersed phase, and asphalt mortar is the first decentralized system of asphalt mixture, with fine aggregate as the dispersed phase scattered in the asphalt medium [1]. The structure, composition, and performance of asphalt mortar have direct influence on the road performance of the asphalt pavement. A lot of research about asphalt mortar [2-6] has been done in terms of the standard Marshall test, immersion Marshall test, rutting test, and low-temperature bending test of beam specimens. Zhang et al. [7] studied the asphalt mortar property with SHRP equipment dynamic shear rheometer (DSR) and bend beam rheometer (BBR), tested and analyzed the effect of filler-bitumen ratio on performance of mortar at high and low temperatures in 2004; and they recommended that the filler-bitumen ratio should not exceed 1.4 for high-temperature performance and not exceed 1.0 for low-temperature performance. But they did not give the minimum value of filler-bitumen ratio, and did not consider additive in asphalt. It has been concluded that modified asphalt by additive can significantly improve the asphalt pavement performance [8-10]. It is still important to explore a proper filler-bitumen ratio to control the asphalt performance.

In this paper, we conducted tests on asphalt mortar with additive SB (Sasobit) and SW (Sasowam) through DSR and BBR. By analyzing test data, the high-temperature anti-rutting and low-temperature crack resistance performance, and the fatigue durability of asphalt mortar are explored. Finally, a filler-bitumen ratio of asphalt mortar is recommended.

\section{Test scheme introduction}

According to the strategic highway research program (SHRP) [11], No. 70 matrix asphalt and limestone ore 
Table 1 Test results of indexes of ore powder and its comparison with technical requirements

\begin{tabular}{lllllll}
\hline & Density $\left(\mathrm{g} / \mathrm{cm}^{3}\right)$ & Hydrophilic coefficient & \multicolumn{4}{l}{ Penetration rate of ore for different siel sizes of screen $(\mathrm{mm})$} \\
\cline { 4 - 6 } & & & 0.6 & 0.3 & 0.15 & 0.075 \\
\hline Test result & 2.730 & 0.76 & 100 & 99.1 & 95.8 & 78.4 \\
Technical requirements & $\nless 2.5$ & $\ngtr 1$ & 100 & - & $90-100$ & $75-100$ \\
\hline
\end{tabular}

powder are used as raw materials to produce the aggregate gradation. The density and hydrophilic coefficient of the ore powder are listed in Table 1.

First, we placed the limestone powder into different sizes of screen mesh to measure penetration rate of the limestone. The obtained results are compared with the technical requirements [1], as shown in Table 1. Then, the ore powder was added into No. 70 matrix asphalt to have asphalt mortar specimens with four filler-bitumen ratios of $0.8,1.0,1.2$, and 1.4 .

\section{High-temperature and fatigue performance of asphalt mortar}

The DSR test is generally used to evaluate the high-temperature characteristics of asphalt mortar $[1,3,5]$. When flat spacing is twice larger than the maximum diameter of rubber cement and the size of the added grain is not more than $0.250 \mathrm{~mm}$, the DSR can be used to test rubber paste properties [12-14].

The DSR in Fig. 1a is used to characterize the viscous and elastic properties of materials by measuring complex material shear modulus $\left(G^{*}\right)$ and phase angle $(\delta)$ [15-17]. DSR can form a piece of thick film between retainer plate and the vibration plate, which are retained under a certain load, and the vibration plate rotates at an angular velocity and angle, as shown in Fig. $1 b$.

The shear stress $\tau$, shear strain $r$, complex modulus $G^{*}$, and phase angle of specimens are calculated by

$$
\tau=\frac{2 T}{\pi r^{3}}, \quad \gamma=\frac{\theta r}{h}, \quad G^{*}=\frac{\tau_{\max }-\tau_{\min }}{\gamma_{\max }-\gamma_{\min }}, \quad \delta=2 \pi f \cdot \Delta t
$$

where $T$ is the maximum torque; $r$ the vibration plate radius; $h$ the sample height; $\theta$ the vibration plate rotation angle; $\tau_{\max }, \tau_{\min }, \gamma_{\max }$, and $\gamma_{\min }$ the maximum or minimum shear stress and strain; $\Delta t$ the lag time.

Under the normal asphalt pavement temperature and traffic load, the viscous and elastic properties of asphalt can be obtained by testing complex shear modulus $G^{*}$, and the relative index $\delta$ between recoverable and non-recoverable deformations. $G^{*} / \sin \delta$ is an anti-rutting factor, indicating distortion resistances of the asphalt material. At the design maximum pavement temperature, the higher the $G^{*} / \sin \delta$, the smaller the deformation of the asphalt. Thus, the higher $G^{*} / \sin \delta$ is more conducive to resist rutting. In addition, $G^{*} \sin \delta$ stands for the capability of the cementing material to resist fatigue [17].

In this experiment, the prepared asphalt mortar was added with SB and SW of $3 \%$ in mass fraction, respectively, as the original specimens; and the original specimens were subjected to aging treatment in rolling thin film oven. We used the original and aging specimens in the DSR test under different temperature conditions. DSR strain is $12 \%$, and angular velocity $\omega=10 \mathrm{rad} / \mathrm{s}$. By applying DSR test, asphalt mortar's fatigue performance was evaluated, that is, rubber paste's rheological properties under the normal temperatures. In Superpave Binder Specifications, fatigue performance is evaluated by applying a pressure to the aging asphalt [18]. SHRP
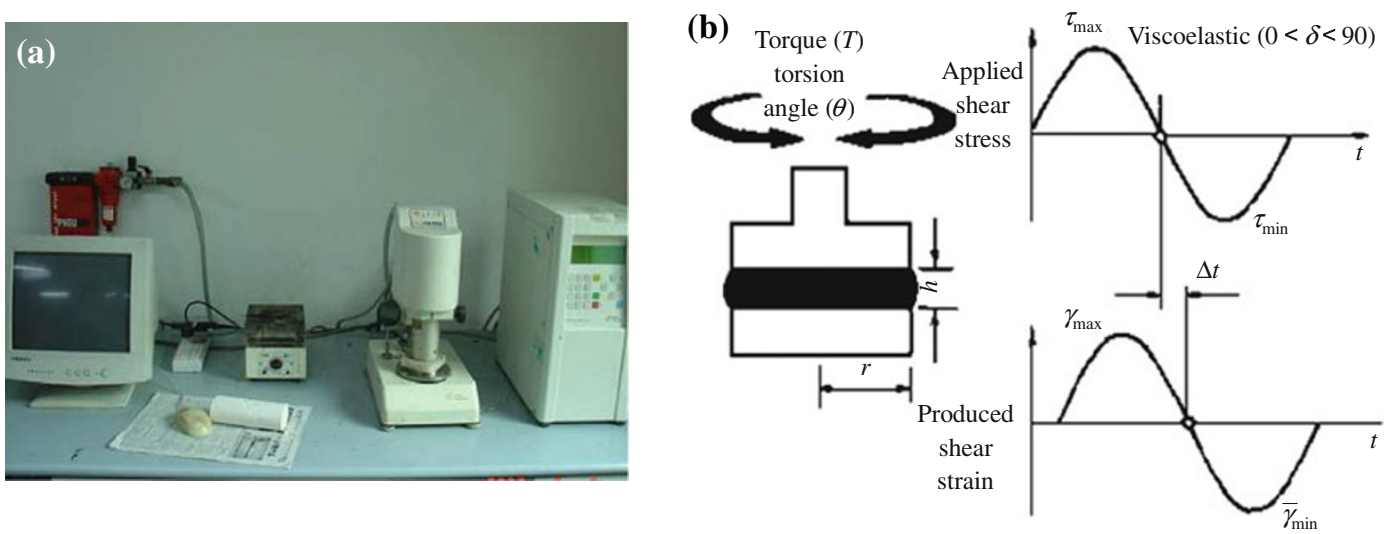

Fig. 1 SHRP dynamic shear flow meter and principle diagram. a Dynamic shear rheometer. b Dynamic shear rheometer working principle 

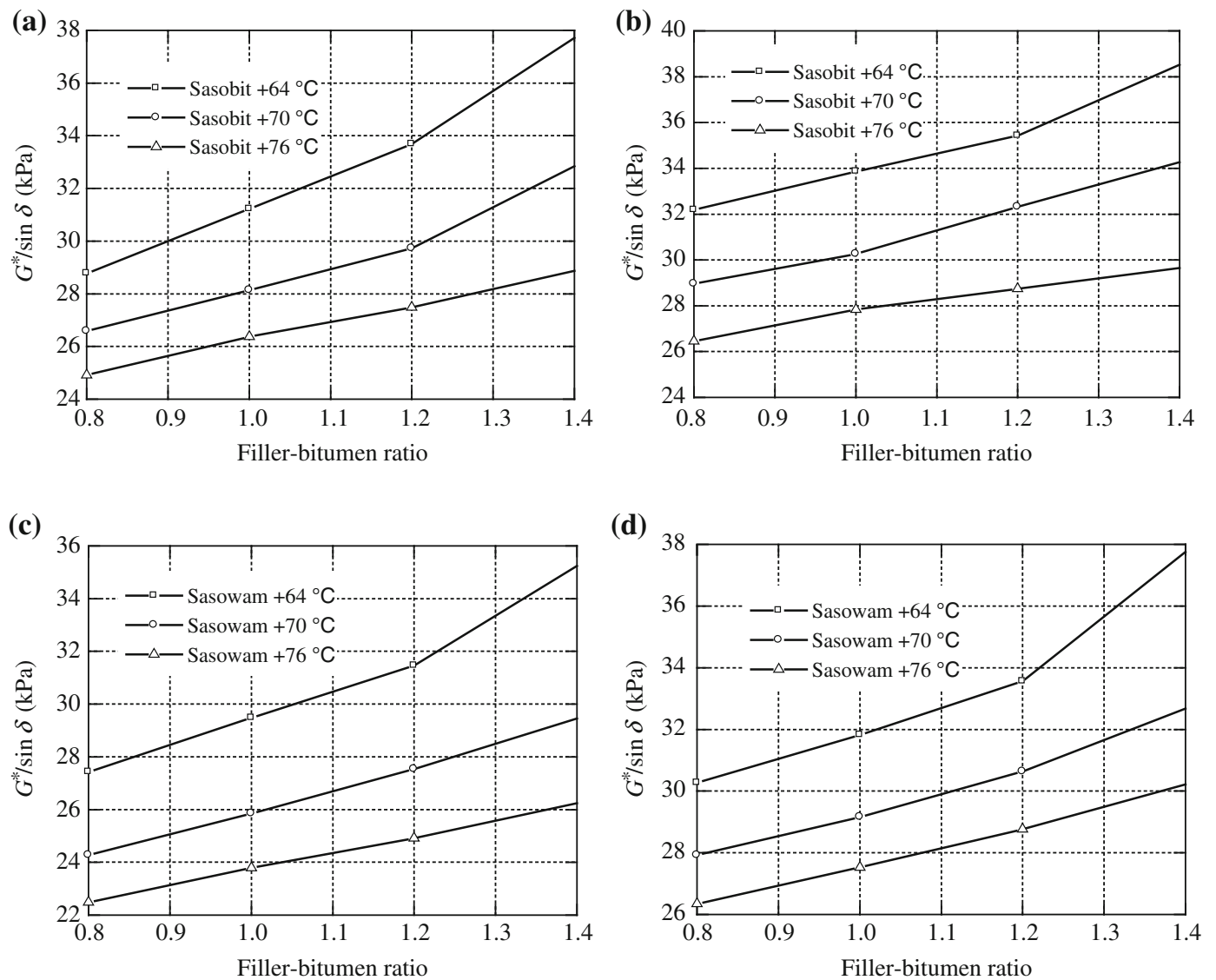

Fig. 2 Relationship between filler-bitumen ratio and rutting factor. a Original specimens with additive SB. b Aging specimens with SB. c Original specimens with SW. d Aging specimens with SW

specifies that $G^{*} \sin \delta$ should not exceed $5,000 \mathrm{kPa}$ in the anti-fatigue cracking performance test [11]. Under different temperatures, the relationship between filler-bitumen ratio and rutting factor can be obtained for the original and aging specimens, as shown in Fig. 2; and the relationship between filler-bitumen ratio and fatigue resistance for the specimens at normal temperatures are shown in Fig. 3.

From Fig. 2, we can reach the following conclusions:

(1) Anti-rutting factor of asphalt mortar increases with filler-bitumen ratio. For the specimens with $\mathrm{SB}$ and $\mathrm{SW}$, the increase of $G^{*} / \sin \delta$ is the largest at $64{ }^{\circ} \mathrm{C}$. When filler-bitumen ratio increases from 0.8 to 1.4 , $G^{*} / \sin \delta$ increases from 28.78 to $37.71,27.43$ to 35.24 for SB and SW, respectively, corresponding to an increment of $31 \%$ and $28.5 \%$. Thus, the hightemperature resistance performance of crack of asphalt mortar with additive SB is better than that with additive SW.

(2) As the temperature and the filler-bitumen ratio increases, the increment of $G^{*} / \sin \delta$ reduces gradually. The filler-bitumen ratio plays an important role in determining the high-temperature performance of asphalt and prevents the asphalt short-term aging. It is necessary to increase filler-bitumen ratio.

From Fig. 3, the following conclusions are drawn:

(1) The increment of $G^{*} \sin \delta$ is $13 \%$ when the fillerbitumen ratio increases from 0.8 to 1.2 . It increases by $20 \%$ when the filler-bitumen ratio increases from 1.2 to 1.4. Obviously, filler-bitumen ratio has a great effect on the fatigue cracking of cementing material.

(2) $G^{*} \sin \delta$ increases when filler-bitumen ratio increases from 0.8 to 1.4 , and the increase rate is relatively stable.

\section{Test analysis of asphalt mortar's performance at low temperature}

Bending beam rheometer in Fig. 4 is an instrument which evaluates the performance of asphalt material at low temperatures [19-21]. It puts asphalt beam specimen on the supporting frame and then loads on it to test the creep stiffness modulus $(S)$ and creep slope $(m)$ of asphalt material. The asphalt binder with smaller $S$ and larger 
(a)

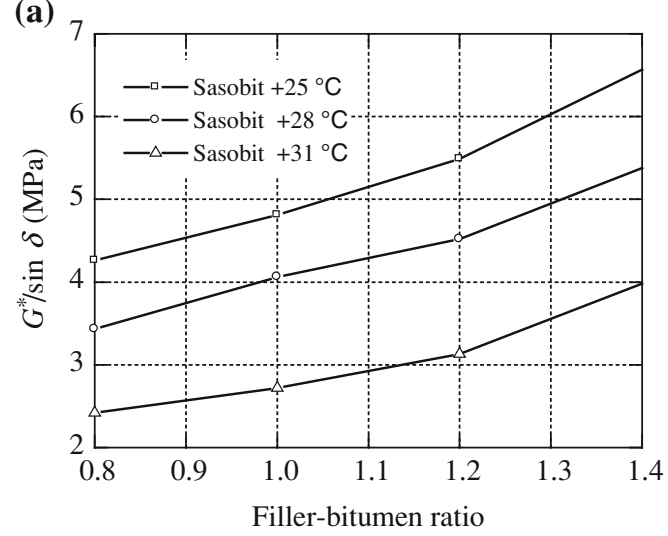

(b)

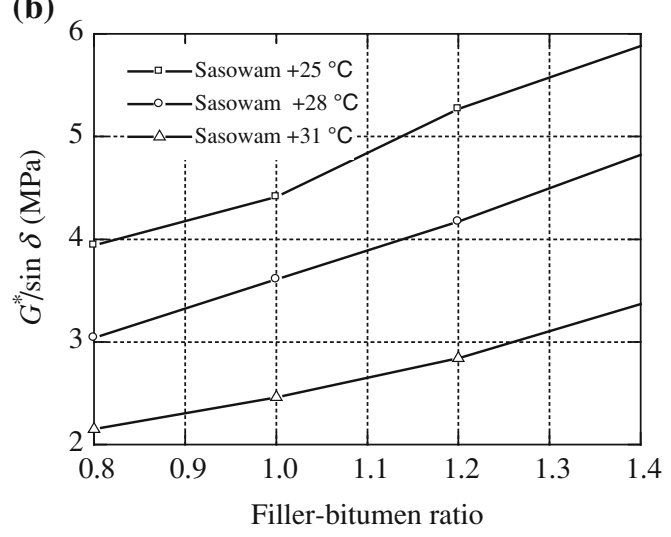

Fig. 3 Relationship between the filler-bitumen ratio and $G^{*} / \sin (\delta)$. a Relationship between the filler-bitumen ratio and $G^{*} \sin (\delta)$ of SB. b Relationship between the filler-bitumen ratio and $G^{*} \sin (\delta)$ of SW

$m$ shows better crack resistance than that with larger $S$ and smaller $m$ at low temperatures.

Bend beam rheometer is recommended to study the lowtemperature performance of the asphalt mortar by many researches for its advantages such as accurate data and good reproducibility [20]. In the process of BBR test, there are three important prerequisites, including time-temperature equivalent relationship, the influence of physical hardening, and linear viscoelasticity, which should be met by BBR test [22].

In this paper, we use the BBR to measure the bending creep stiffness modulus $S$ and creep rate $m$ at $-18,-12$, and $-6{ }^{\circ} \mathrm{C}$, respectively, and the results are shown in Figs. 5 and 6.

From Fig. 5, we obtain the following conclusions:

(1) The low-temperature resistance performance of asphalt mortar becomes worse with the increase of fillerbitumen ratio, especially when the ratio increases from 1.2 to 1.4. Its performance falls fast at low temperature, and the decrease of temperature also has a great influence on the stiffness modulus of rubber paste.
(2) The creep rate decreases gradually with the increase of filler-bitumen ratio, and the crack resistance decreases rapidly at low temperature when the filler-bitumen ratio exceeds 1.2.

From Fig. 6, it is seen that with the increase of fillerbitumen ratio, creep stiffness modulus increases; that is, the low-temperature anti-cracking performance of the mortar becomes worse with the increase of filler-bitumen ratio. At the same time, the temperature also has a great impact on the rubber paste's stiffness modulus when it decreases. Amplitude of creep rate does not reduce significantly. Hence the filler-bitumen ratio of asphalt mortar with additive SW can be a little larger than that of SB.

\section{Ductility test analysis for asphalt mortar}

The interaction of asphalt and additive not only has great influence on the formation and the quantity of the asphalt

(b)
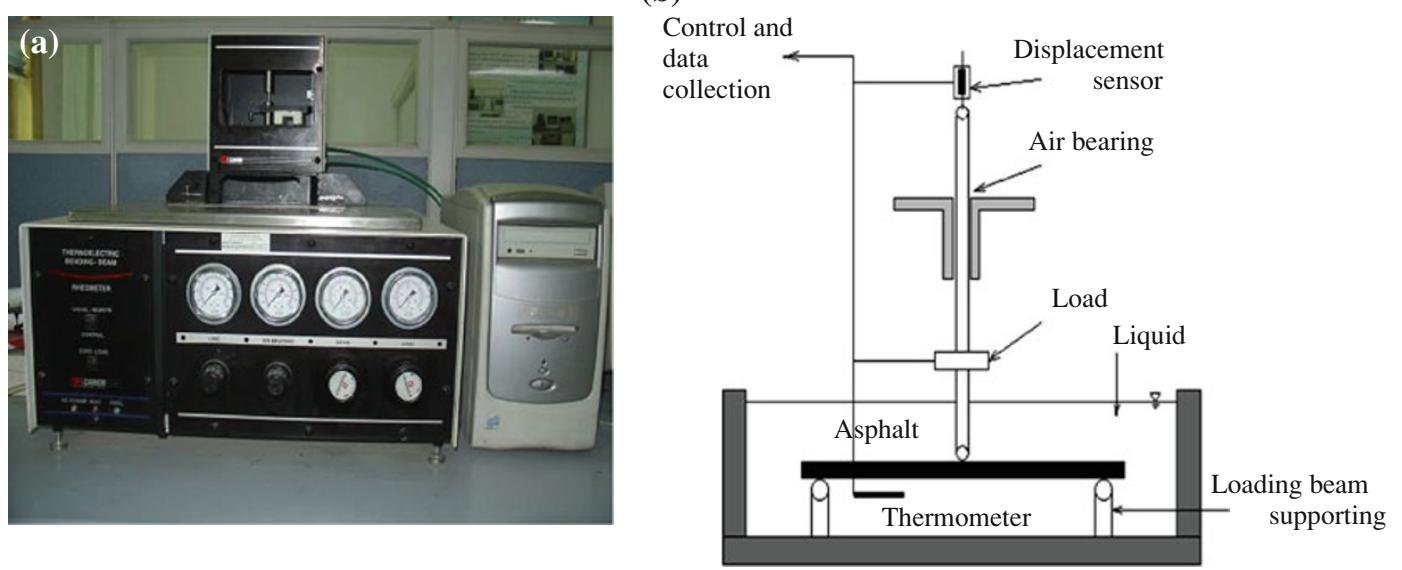

Fig. 4 Bending beam rheometer and its principle diagram. a Photo. b Work principle 
(a)

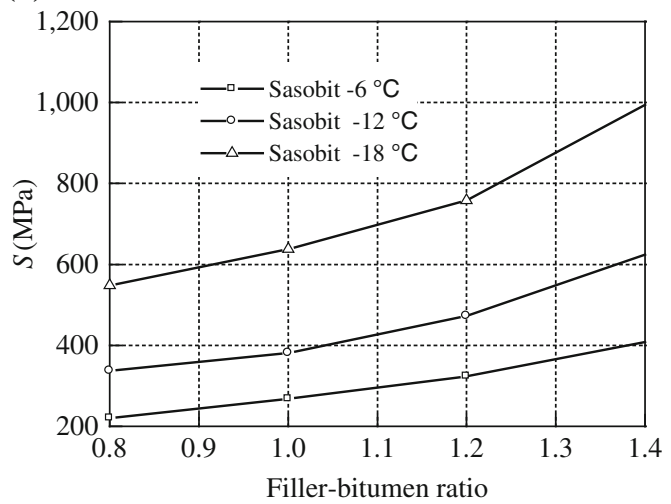

(b)

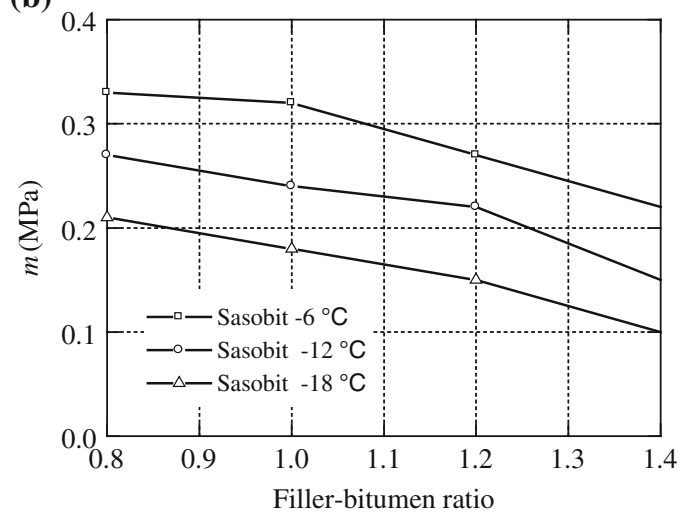

Fig. 5 BBR test results of SB modified asphalt mortar. a Bending creep stiffness modulus versus filler-bitumen ratio. b Creep rate versus fillerbitumen ratio

(a)

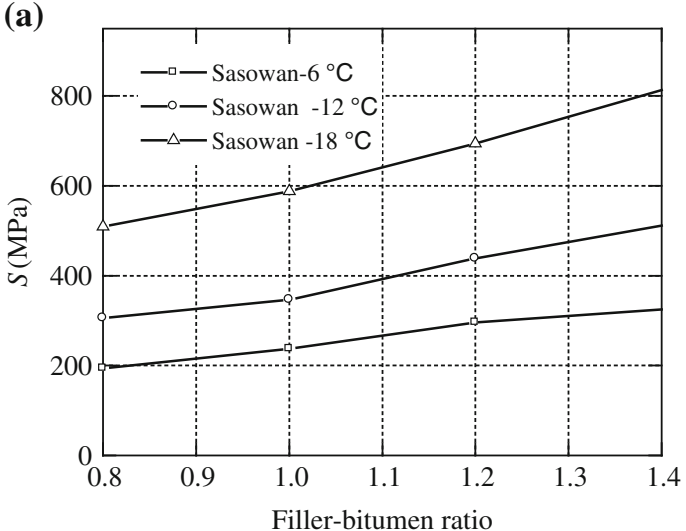

(b)

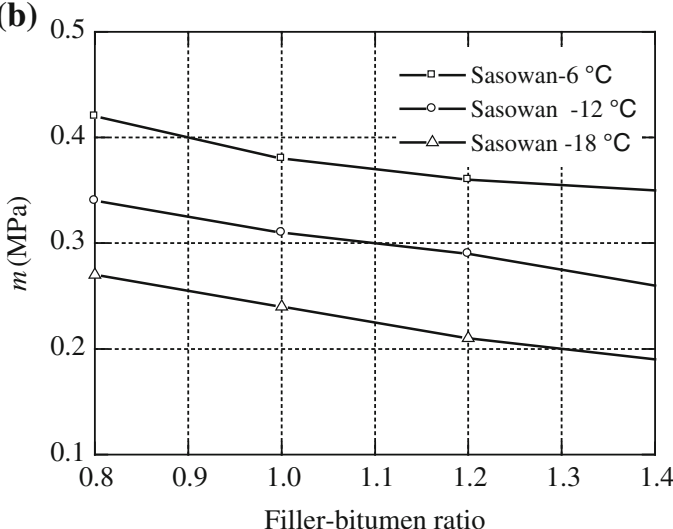

Fig. 6 BBR test results of SW modified asphalt mortar. a Bending creep stiffness modulus versus filler-bitumen ratio. b Creep rate versus fillerbitumen ratio

Table 2 Test results of modified asphalt's ductility $(\mathrm{cm})$

\begin{tabular}{llllll}
\hline Additive & Temperature $\left({ }^{\circ} \mathrm{C}\right)$ & \multicolumn{5}{l}{ Filler-bitumen ratio } \\
\cline { 3 - 6 } & & 0.8 & 1.0 & 1.2 & 1.4 \\
\hline SB & 25 & 4.26 & 4.81 & 5.49 & 6.57 \\
& 28 & 3.43 & 4.06 & 4.52 & 5.38 \\
& 33 & 2.42 & 2.72 & 3.13 & 3.98 \\
SW & 25 & 3.94 & 4.41 & 5.27 & 5.88 \\
& 28 & 3.04 & 3.61 & 4.17 & 4.82 \\
& 33 & 2.15 & 2.46 & 2.84 & 3.37 \\
\hline
\end{tabular}

mortar's structure, but also has great influence on its viscosity and low-temperature brittleness [22-24]. The ductility of asphalt mortar, compared to asphalt mixture, is more accurate to reflect the low-temperature ductility. This paper discusses ductility value of the asphalt mortar at a certain tensile speed $(5 \mathrm{~cm} / \mathrm{min})$ under the different filler-bitumen ratios and different temperature conditions. Test results of ductility values of the asphalt mortar are shown in Table 2 and Fig. 7.

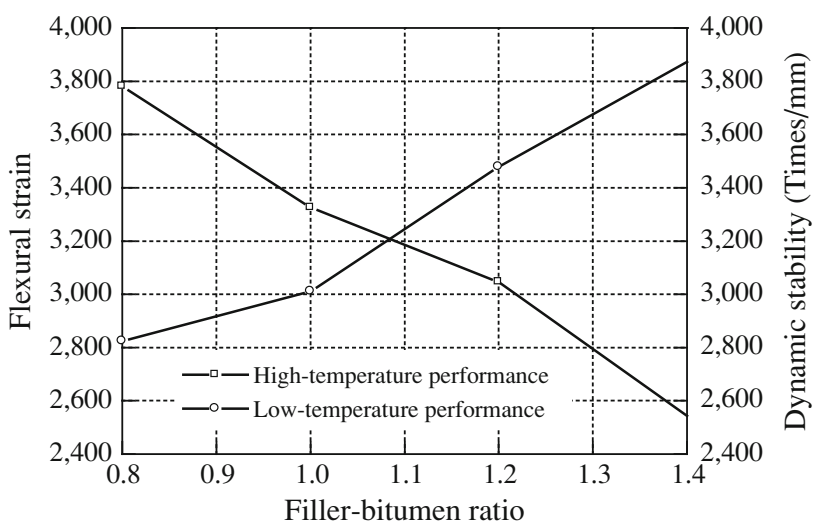

Fig. 7 Test results of SB modified asphalt mixture at high and low temperatures

Table 2 shows that the ductility of the asphalt mortar decreases with the increase of filler-bitumen ratio. Hence, the filler-bitumen ratio should not be too great. Here we suggest that it should be less than 1.2. 
From Fig. 7 one can see that the bending strain at low temperature decreases gradually with the increase of fillerbitumen ratio, and the low-temperature performance reduces sharply when filler-bitumen ratio continues to increase from 1.2 to 1.4. However, the high-temperature performance increases gradually with the increase of fillerbitumen ratio. Compared to the low-temperature performance, the high-temperature performance has smaller increase amplitude when filler-bitumen ratio continues to increase from 1.2 to 1.4. According to the high-temperature and low-temperature performance results, the filler-bitumen ratio of asphalt mortar with additive SB should be less than 1.2 .

\section{Conclusions}

(1) According to the above research results, we know that rutting factor increases gradually with the fillerbitumen ratio and has a largest amplitude at $64{ }^{\circ} \mathrm{C}$. The increment of rutting factor decreases with temperature. The filler-bitumen ratio of asphalt mortar with additive SB has a larger effect on anti-rutting factor at low temperature than that of SW. The increment of anti-rutting factor after aging treatment becomes smaller than that of before aging, which shows that ore powder can prevent asphalt aging. Thus, ore powder not only can increase the anti-rutting factor but also can increase the aging resistance of asphalt.

(2) According to two additives' performances and different testing temperatures, the influence of SB on anti-rutting factor is greater than that of SW. Hence, $\mathrm{SB}$ has better performances than SW at high temperatures.

(3) With the increase of ore powder's dosage, anti-rutting factor increases gradually, and the increasing amplitude is less affected by temperature. When the fillerbitumen ratio reaches 1.2 , the fatigue factor of the asphalt mortar with SB increases significantly; while for $\mathrm{SW}$ it is not so obvious. Compared to SB, the fatigue factor of the specimens with SW has smaller amplitude increase. Hence, the filler-bitumen ratio of SB should be less than 1.2.

(4) According to low-temperature performance test, when the filler-bitumen ratio of the asphalt mortar with SB continues to increase above 1.2, creep stiffness modulus increases rapidly, while creep rate and ductility decrease rapidly in the ductility test. Hence, filler-bitumen ratio for that of SB should be less than 1.2, while that of SW can be larger than 1.2 since SW has better performances than SB at low temperatures.
(5) The influence of additive on asphalt mortar performance can be obtained through the high-temperature and low-temperature and ductility tests on warm mix asphalt mortar. The recommended range of fillerbitumen ratio of the asphalt mortar with SB is between 0.8 and 1.2 .

Open Access This article is distributed under the terms of the Creative Commons Attribution License which permits any use, distribution, and reproduction in any medium, provided the original author(s) and the source are credited.

\section{References}

1. Zhang ZQ, Wang YC (2006) Influence of asphalt mortar on hot mix asphalt performance at high and low temperature. J Chang'an Univ Nat Sci Ed 26(2):1-5 (in Chinese)

2. Feng H (2008) Research on experimentation characteristic of asphalt mortar with viseo-elasticity theory. Dissertation, University of Science and Technology, Changsha (in Chinese)

3. Brice D, Herve DB, Pierre C et al (2007) Linear viscoelastic properties of bituminous materials: from binders to mastics (with discussion), J Assoc Asph Paving Technol 76:455-494

4. Brown ER, Haddock JE, Crawford C (1996) Investigation of stone matrix asphalt mortars. J Transp Res Board 1530: 95-102

5. Gubler R, Liu Y, Anderson DA et al (1999) Investigation of the system filler and asphalt binders by rheological means. Association of Asphalt Paving Technologists, 68(2):284-304

6. Witczak MW, Kaloush K, Pellinen T (2002) Simple performance test for super-pave mix design. Transportation Research Board, National Research Council. National Academy Press, Washington, pp $172-180$

7. Zhang ZQ, Zhang WP, Li P (2004) Ratio of filler bitumen of asphalt mixture. J Chang'an Univ Nat Sci Ed 24(5):7-10 (in Chinese)

8. Kim YR, Little DN (2004) Linear viscoelastic analysis of asphalt mastics. J Mater Civil Eng 16(2):122-132

9. Yousefi AA, Kadi AA, Roy C (2000) Composite asphalt binders: effect of modified RPE on asphalt. J Mater Civil Eng 12(2): $113-123$

10. Neguleseu II, Daly WH, Mohammad LN et al (2000) Recycling of polymer modified asphalt pavement-a binder study. Transportation Research Board 79th Annual Meeting, Washington, DC, 9-13 Jan 2000

11. American Association of State Highway and Transportation Officials (1993) AASHTO guide for design of pavement structures. AASHTO, Washington

12. National Cooperative Highway Research Program, Guide for mechanistic empirical design of new and rehabilitated pavement structures final report. http://www.betterroads.com/tag/guide-formechanistic-empirical-design-of-new-and-rehabilitated-pavementstructures-final-report-nchrp-2004/. Accessed 1 Sep 2004

13. American Association of State Highway Transportation Officials, method of test for determining rutting susceptibility of asphalt paving mixtures using the asphalt pavement analyzer. http://www.okladot. state.ok.us/materials/pdfs-ohdl/ohdl43.pdf. Accessed 14 July 2009

14. Ministry of transportation (2008) Technical specifications for construction of highway asphalt pavements. China Communications Press, Beijing (in Chinese)

15. Huang YB, Qin L (2005) Methods to improve asphalts and discussion of improved asphalts capacity. J Guangxi Univ Nat Sci Ed 30(1):122-124 (in Chinese) 
16. Chen HX, Yuan YJ, Zhang ZQ et al (2005) Influencing factors in dynamic shear rheometer tests. Central South Highw Eng 30(2):142-164 (in Chinese)

17. The Federal Aviation Administration (2008) Hot mix asphalt mixture calculates the manual. People's Communication Press, Beijing (in Chinese)

18. Duan SR, Ren RB (2001) Application of dynamic shear rheometer (DSR) evaluation of pavement performance. Central South Highw Eng 4:81-83

19. Lin XX (2002) The discussion on the Superpave composition ratio characteristic. East China Highw 2:45-47 (in Chinese)

20. Feng IL (2006) Rheological analysis of asphalt tested by bending beam rheometer. J Wuhan Univ Technol 30(2):205-208 (in Chinese)
21. Li YW, Wang JS, Huang WY et al (2011) Warm mix asphalt pavement construction technology. China Architecture \&Building Press, Beijing (in Chinese)

22. Zhang YL (2011) Asphalt pavement construction technology and quality control. People's Communication Press, Beijing (in Chinese)

23. Li YS (1995) Creep and relaxation of 4 kinds of rock under uniaxial compression tests. Chin J Rock Mech Eng 14(1):39-47 (in Chinese)

24. Zheng NX, Zhang X, Li A (2004) Discuss of problems in SHRP performance grading system. J Highw Transp Res Dev 9:55-59 (in Chinese) 